\begin{tabular}{|c|c|c|}
\hline \multirow{3}{*}{$\begin{array}{r}\text { Case Reports in } \\
\text { Gastroenterology }\end{array}$} & \multirow{2}{*}{\multicolumn{2}{|c|}{ Case Rep Gastroenterol 2013;7:449-454 }} \\
\hline & & \\
\hline & $\begin{array}{l}\text { DOI: 10.1159/000355939 } \\
\text { Published online: October 9, } 2013\end{array}$ & $\begin{array}{l}\text { ○ } 2013 \text { S. Karger AG, Basel } \\
\text { 1662-0631/13/0073-0449 } \$ 38.00 / 0 \\
\text { www.karger.com/crg }\end{array}$ \\
\hline & \multicolumn{2}{|c|}{$\begin{array}{l}\text { This is an Open Access article licensed under the terms of the Creative Commons } \\
\text { Attribution-NonCommercial } 3.0 \text { Unported license (CC BY-NC) (www.karger.com/OA } \\
\text { license), applicable to the online version of the article only. Distribution permitted for non } \\
\text { commercial purposes only. }\end{array}$} \\
\hline
\end{tabular}
commercial purposes only.

\title{
Small-Sized, Flat-Type Invasive Branch Duct Intraductal Papillary Mucinous Neoplasm: A Case Report
}

\author{
Koji Shindo ${ }^{a, b} \quad J^{\prime}$ ji Ueda ${ }^{b}$ Shinichi Aishima ${ }^{a} \quad$ Akira Aso $^{c}$ \\ Takao Ohtsuka $^{b}$ Shunichi Takahata ${ }^{b}$ Kousei Ishigami $^{d}$ Yoshinao Oda $^{a}$ \\ Masao Tanaka ${ }^{b}$ \\ Departments of a Anatomic Pathology, ${ }^{b}$ Surgery and Oncology, ${ }^{c}$ Medicine and \\ Bioregulatory Science and ${ }^{\mathrm{d}}$ Clinical Radiology, Graduate School of Medical Sciences, \\ Kyushu University, Fukuoka, Japan
}

\section{Key Words}

Intraductal papillary mucinous neoplasm · Branch duct · Small-sized · Cytology · International consensus guidelines

\begin{abstract}
Recent improvements in diagnostic modalities are increasing the frequency of detection of small-sized branch duct intraductal papillary mucinous neoplasms (BD-IPMNs). International consensus guidelines for IPMN recommend surveillance without immediate resection for small-sized $(<3 \mathrm{~cm})$ BD-IPMNs without malignant features on imaging. Our patient is the first to have undergone resection of a small-sized BD-IPMN containing invasive cancer, but without malignant features on imaging. We herein report a case involving a 70-year-old man with a small cystic lesion in the pancreas head detected by health screening ultrasonography. Detailed examination revealed that the cystic lesion was a BD-IPMN measuring about $2 \mathrm{~cm}$, with no malignant features. However, cytological examination of the pancreatic juice showed atypical cells with high-grade dysplasia storing intracytoplasmic mucin, indicating malignant BD-IPMN. Pathological examination of the resected specimen showed a BD-IPMN measuring $16 \mathrm{~mm}$ with an associated invasive carcinoma that invaded the pancreatic parenchyma over a distance of $11 \mathrm{~mm}$. In this patient, invasive cancer was present within a small BD-IPMN with no high-risk stigmata on imaging. Cytological examination of the pancreatic juice allowed for the detection of pancreatic cancer in such a small-sized IPMN. Although routine endoscopic retrograde cholangiopancreatography (ERCP) with cytology is not recommended in all patients with BD-IPMNs, ERCP may contribute to the detection of small pancreatic cancers in select cases. Accumulation of cases of pancreatic cancer within small BD-IPMNs may help
\end{abstract}


Shindo et al.: Small-Sized, Flat-Type Invasive Branch Duct Intraductal Papillary Mucinous Neoplasm: A Case Report

establish the indications for ERCP with cytological examination for the purpose of early detection of small pancreatic cancer.

(c) 2013 S. Karger AG, Basel

\section{Introduction}

Intraductal papillary mucinous neoplasm (IPMN) of the pancreas is characterized by cystic dilation of the main and/or branch pancreatic duct and arrangement of intraductal proliferation of neoplastic mucinous cells into papillary structures [1]. IPMNs have a wide spectrum of atypical grades, ranging from low-grade dysplasia to invasive carcinoma [1]. Recent improvements in radiologic imaging have been increasing the frequency of detection of small-sized IPMNs [2]. The international consensus guidelines of IPMN by the International Association of Pancreatology were revised in 2012 and now include an algorithm for the management of branch duct IPMNs (BD-IPMNs). For BD-IPMNs with (i) obstructive jaundice, (ii) an enhancing solid component within the cyst and (iii) a main pancreatic duct (MPD) of $\geq 10 \mathrm{~mm}$ in size, immediate surgical resection is recommended. On the other hand, for small-sized BD-IPMNs of $<3 \mathrm{~cm}$ without these high-risk stigmata on imaging, surveillance is recommended [3]. The guidelines suggest that malignant disease rarely exists within small-sized BD-IPMNs of $<3 \mathrm{~cm}$ without high-risk stigmata on imaging. We herein report the surgical resection of invasive carcinoma within a small-sized BD-IPMN of $<3 \mathrm{~cm}$ with no high-risk stigmata on imaging; the lesion was diagnosed by endoscopic retrograde cholangiopancreatography (ERCP) with cytological examination.

\section{Case Report}

A 70-year-old man was referred to our hospital for evaluation of a small cystic lesion in the pancreas head detected by health screening ultrasonography. He had neither clinical symptoms nor abnormal physical findings. Routine laboratory data also showed no abnormalities. Serum levels of carcinoembryonic antigen and carbohydrate antigen 19-9 were within normal limits. Enhanced computed tomography (CT) revealed a 17-mm cystic lesion without a solid component in the pancreas head. The cystic lesion was connected to the MPD (fig. 1a). Magnetic resonance cholangiopancreatography revealed that the cystic lesion was multilocular and connected to the MPD, which was not dilated (fig. 1b). On endoscopic ultrasonography (EUS), neither mural nodules nor wall thickness within the cystic lesion were detected (fig. 1c). ERCP revealed a 15-mm cystic dilation of the branch ducts without dilation of the MPD (fig. 1d). The cystic lesion had no features suggesting malignancy such as a cyst size of $\geq 3 \mathrm{~cm}$, dilation of the MPD or an enhancing solid component within the cyst. However, cytological examination of the pancreatic juice collected during ERCP showed atypical columnar cells with loss of polarity, enlarged and hyperchromatic irregular nuclei and partially intracytoplasmic mucin (fig. 2). These results suggested atypical cells with high-grade dysplasia, and the cystic lesion was diagnosed as a malignant BD-IPMN.

Pylorus-preserving pancreatoduodenectomy was performed. Intraoperative lavage cytology of the MPD of the remnant pancreas revealed no atypical cells. Pathological examination of the resected specimen showed a multilocular cystic lesion (fig. 3a), $16 \times 9 \times 15 \mathrm{~mm}$ in size, composed of dilated pancreatic branch ducts lined by columnar epithelium with mostly low-grade to focally high-grade dysplasia showing micropapillary growth (fig. 3b). In addition, small nests of irregular glands with enlarged nuclei invading the pancreatic parenchyma were noted over a distance of $11 \mathrm{~mm}$, surrounded by myxoid stroma (fig. 3c). These 
Shindo et al.: Small-Sized, Flat-Type Invasive Branch Duct Intraductal Papillary Mucinous Neoplasm: A Case Report

features were consistent with the histological diagnosis of IPMN with an associated invasive carcinoma. Immunohistochemically, the neoplastic cells were positive for MUC5AC and MUC6, but negative for MUC1, MUC2 and CDX2, suggesting gastric-type IPMN.

\section{Discussion}

The international consensus guidelines recommend surgical resection for all patients with a BD-IPMN with MPD dilation of $>10 \mathrm{~mm}$ because of the high incidence of malignant/invasive lesions and the low 5-year survival rate (31-54\%) [3]. For BD-IPMNs, the 2006 guidelines recommended surgical resection in patients with clinical symptoms, mural nodules, a dilated MPD, cyst size of $\geq 3 \mathrm{~cm}$ or positive cytology [4]. The analysis of a large cohort of resected BD-IPMNs confirmed that these criteria were sensitive and effective for the diagnosis of malignancy [5]. However, cyst size as a weak indicator for surgical resection was excluded from the high-risk stigmata of BD-IPMN in the 2012 revised guidelines, which included (i) obstructive jaundice due to a cystic lesion in the pancreas head, (ii) enhancing solid components within the cyst, and (iii) an MPD of $\geq 10 \mathrm{~mm}$ in size. A cyst size of $\geq 3 \mathrm{~cm}$ has been defined as a 'worrisome feature' that advocates evaluation by EUS to further riskstratify the lesion. Other 'worrisome features' on imaging include a cyst size of $\geq 3 \mathrm{~cm}$, thickened and enhanced cyst walls, an MPD size of 5-9 mm, nonenhanced mural nodules, an abrupt change in MPD caliber with distal pancreatic atrophy, and lymphadenopathy. All patients with a cyst $\leq 3 \mathrm{~cm}$ and no 'worrisome features' are recommended to undergo surveillance. Routine ERCP for sampling of fluid or brushing in patients with IPMNs is not recommended and should primarily be used in the context of research [3].

In our patient, the cyst size was only $17 \mathrm{~mm}$, and no 'worrisome features' were present. However, surgical resection was performed because cytological examination by ERCP revealed cancer cells. In the resected specimen, gastric-type cancer cells invading the pancreatic parenchyma were present within the cyst wall. Gastric-type IPMNs are usually lowgrade, but when they develop invasive carcinoma, they behave similar to pancreatic ductal adenocarcinoma (PDAC). If cytological examination had not been performed in this patient, surveillance by CT, magnetic resonance imaging and EUS might have been carried out, and surgical resection might have been postponed until the appearance of 'high-risk stigmata' and spreading of cancer cells. Our patient underwent surgical resection before cancer spread because of the positive cytological examination findings.

In previous studies of large series of BD-IPMNs, malignant BD-IPMNs $<3 \mathrm{~cm}$ without mural nodules were occasionally described, but details were not mentioned [6-8]. A study of flat-type BD-IPMNs without mural nodules from our institution showed no single case of a malignant BD-IPMN $<3 \mathrm{~cm}$ [9]. This is the first case of malignant flat-type BD-IPMN $<3 \mathrm{~cm}$ in our experience. Although the ERCP technique sometimes results in acute pancreatitis as a complication, cytological examination of the pancreatic juice seems to be useful in detecting small-sized malignant BD-IPMNs in select cases. Accumulation of cases of small-sized malignant IPMNs similar to that in our patient may help define the indications for ERCP with cytology in patients with small-sized BD-IPMNs.

In addition to the malignant transformation of IPMN, concomitant PDAC is not infrequently observed in patients with IPMN. Maguchi et al. [10] reported that $17.8 \%$ of BD-IPMNs without an operative indication exhibited disease progression, and concomitant but distinct PDAC occurred in 7 of 347 patients (2\%) during long-term follow-up. In the follow-up of IPMN, special attention should be paid to the development of concomitant PDAC [11]. ERCP with cytology may be useful to detect not only malignant IPMN, but also 
Shindo et al.: Small-Sized, Flat-Type Invasive Branch Duct Intraductal Papillary Mucinous Neoplasm: A Case Report

small-sized concomitant PDAC [12-14]. However, the selection criteria for the indication of ERCP with cytology remain unclear.

In conclusion, in view of the present patient with a small-sized malignant IPMN diagnosed only by ERCP with cytology, attention should be given to patients with small-sized IPMNs with neither 'high-risk stigmata' nor 'worrisome features'. Even a small-sized IPMN without malignant features on imaging may be associated with invasive cancer. Cytological examination may allow for the detection of small-sized pancreatic malignancy, either malignant BD-IPMN or concomitant PDAC. Accumulation of cases of pancreatic cancer within small-sized BD-IPMNs may help establish the indications for ERCP with cytological examination for the purpose of early detection of small-sized pancreatic cancers.

\section{Disclosure Statement}

The authors have no conflict of interest.

\section{References}

1 Adsay NV, Fukushima N, Furukawa T, Hruban RH, Klimstra DS, Klöppel G, Offerhaus GJA, Pitman MB, Shimizu M, Zamboni G: Intraductal neoplasms of the pancreas; in Bosman FT, Carneiro F, Hruban RH, Theise ND (eds): WHO Classification of Tumours of the Digestive System. Lyon, IARC, 2010, pp 304-313.

-2 Sohn TA, Yeo CJ, Cameron JL, Hruban RH, Fukushima N, Campbell KA, Lillemoe KD: Intraductal papillary mucinous neoplasms of the pancreas: an updated experience. Ann Surg 2004,239:788-797; discussion 797-799.

-3 Tanaka M, Fernandez-del Castillo C, Adsay V, Chari S, Falconi M, Jang JY, Kimura W, Levy P, Pitman MB, Schmidt CM, Shimizu M, Wolfgang CL, Yamaguchi K, Yamao K; International Association of Pancreatology: International consensus guidelines 2012 for the management of IPMN and MCN of the pancreas. Pancreatology 2012;12:183-197.

-4 Tanaka M, Chari S, Adsay V, Fernandez-del Castillo C, Falconi M, Shimizu M, Yamaguchi K, Yamao K, Matsuno S; International Association of Pancreatology: International consensus guidelines for management of intraductal papillary mucinous neoplasms and mucinous cystic neoplasms of the pancreas. Pancreatology 2006;6:17-32.

5 Rodriguez JR, Salvia R, Crippa S, Warshaw AL, Bassi C, Falconi M, Thayer SP, Lauwers GY, Capelli P, Mino-Kenudson M, Razo O, McGrath D, Pederzoli P, Fernandez-del Castillo C: Branch-duct intraductal papillary mucinous neoplasms: observations in 145 patients who underwent resection. Gastroenterology 2007;133:72-79; quiz 309-310.

6 Woo SM, Ryu JK, Lee SH, Yoon WJ, Kim YT, Yoon YB: Branch duct intraductal papillary mucinous neoplasms in a retrospective series of 190 patients. Br J Surg 2009;96:405-411.

7 Nagai K, Doi R, Kida A, Kami K, Kawaguchi Y, Ito T, Sakurai T, Uemoto S: Intraductal papillary mucinous neoplasms of the pancreas: clinicopathologic characteristics and long-term follow-up after resection. World J Surg 2008;32:271-278; discussion 279-280.

-8 Jang JY, Kim SW, Lee SE, Yang SH, Lee KU, Lee YJ, Kim SC, Han DJ, Choi DW, Choi SH, Heo JS, Cho BH, Yu HC, Yoon DS, Lee WJ, Lee HE, Kang GH, Lee JM: Treatment guidelines for branch duct type intraductal papillary mucinous neoplasms of the pancreas: when can we operate or observe? Ann Surg Oncol 2008;15:199-205.

-9 Sadakari Y, Ienaga J, Kobayashi K, Miyasaka Y, Takahata S, Nakamura M, Mizumoto K, Tanaka M: Cyst size indicates malignant transformation in branch duct intraductal papillary mucinous neoplasm of the pancreas without mural nodules. Pancreas 2010;39:232-236.

10 Maguchi H, Tanno S, Mizuno N, Hanada K, Kobayashi G, Hatori T, Sadakari Y, Yamaguchi T, Tobita K, Doi R, Yanagisawa A, Tanaka M: Natural history of branch duct intraductal papillary mucinous neoplasms of the pancreas: a multicenter study in Japan. Pancreas 2011;40:364-370.

-11 Uehara H, Nakaizumi A, Ishikawa O, Iishi H, Tatsumi K, Takakura R, Ishida T, Takano Y, Tanaka S, Takenaka A: Development of ductal carcinoma of the pancreas during follow-up of branch duct intraductal papillary mucinous neoplasm of the pancreas. Gut 2008;57:1561-1565.

12 Schmidt CM, White PB, Waters JA, Yiannoutsos CT, Cummings OW, Baker M, Howard TJ, Zyromski NJ, Nakeeb A, DeWitt JM, Akisik FM, Sherman S, Pitt HA, Lillemoe KD: Intraductal papillary mucinous neoplasms: predictors of malignant and invasive pathology. Ann Surg 2007;246:644-651; discussion 651-654. 


\section{Case Reports in
Gastroenterology}

\begin{tabular}{l|l}
\hline Case Rep Gastroenterol 2013;7:449-454 \\
\hline DOI: $10.1159 / 000355939$ & $\begin{array}{l}\text { ○ } 2013 \text { S. Karger AG, Basel } \\
\text { www.karger.com/crg }\end{array}$ \\
\hline
\end{tabular}

Shindo et al.: Small-Sized, Flat-Type Invasive Branch Duct Intraductal Papillary Mucinous Neoplasm: A Case Report

13 Genevay M, Mino-Kenudson M, Yaeger K, Konstantinidis IT, Ferrone CR, Thayer S, Castillo CF, Sahani D, Bounds B, Forcione D, Brugge WR, Pitman MB: Cytology adds value to imaging studies for risk assessment of malignancy in pancreatic mucinous cysts. Ann Surg 2011;254:977-983.

14 Ono J, Yaeger KA, Genevay M, Mino-Kenudson M, Brugge WR, Pitman MB: Cytological analysis of small branch-duct intraductal papillary mucinous neoplasms provides a more accurate risk assessment of malignancy than symptoms. Cytojournal 2011;8:21.
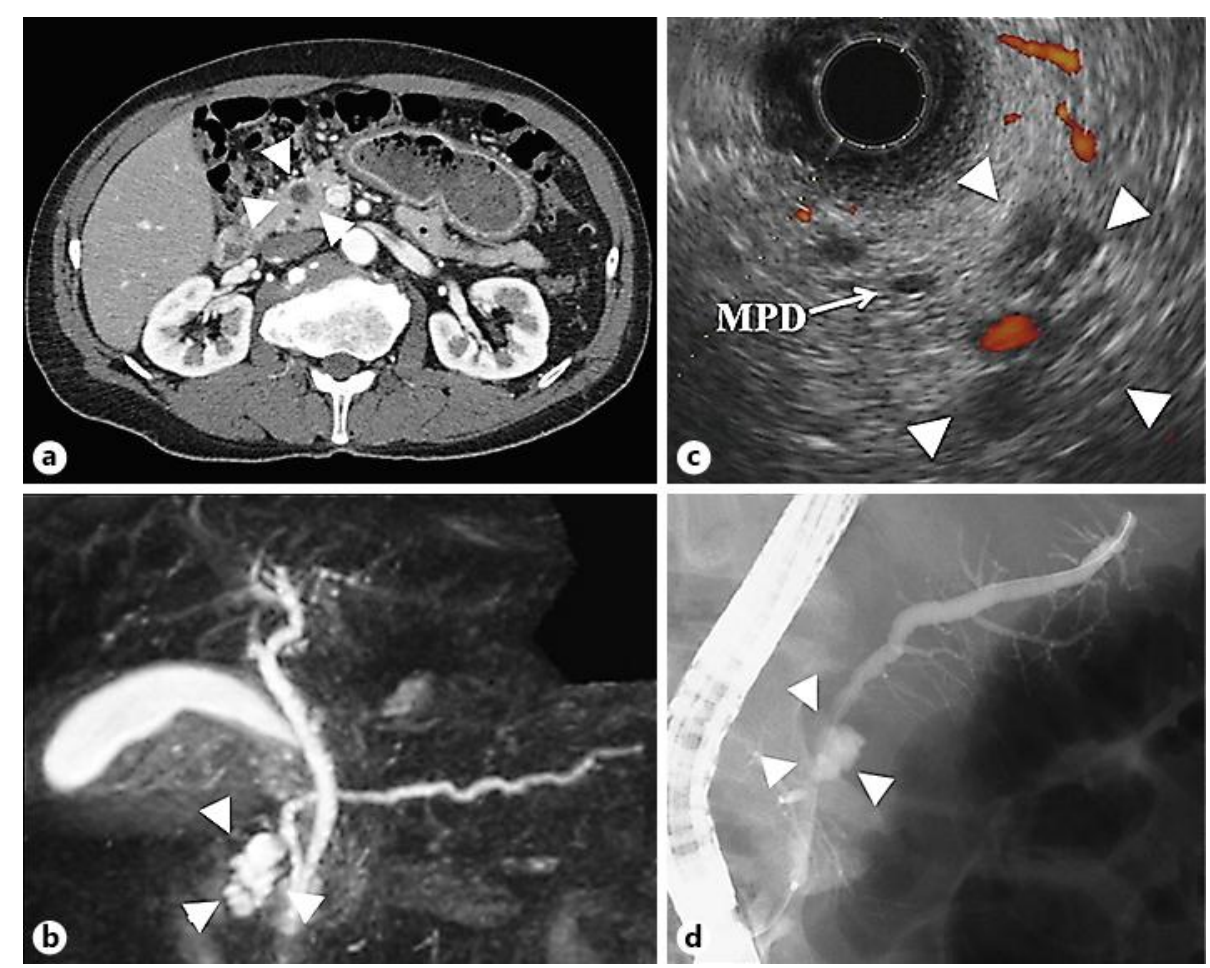

Fig. 1. a Enhanced CT revealed a cystic lesion (arrowheads) without a solid component in the pancreas head. b Magnetic resonance cholangiopancreatography revealed that the cystic lesion (arrowheads) was multilocular and connected to the MPD. c EUS revealed a multilocular lesion (arrowheads) with neither mural nodules nor wall thickness. d ERCP revealed cystic dilation of the branch ducts measuring $15 \mathrm{~mm}$ (arrowheads) without dilation of the MPD. 


\begin{tabular}{rll} 
Case Reports in & \multicolumn{2}{l}{ Case Rep Gastroenterol 2013;7:449-454 } \\
\cline { 2 - 3 } Gastroenterology & DOI: 10.1159/000355939 & $\begin{array}{l}\text { ○ 2013 S. Karger AG, Basel } \\
\text { www.karger.com/crg }\end{array}$ \\
\hline
\end{tabular}

Shindo et al.: Small-Sized, Flat-Type Invasive Branch Duct Intraductal Papillary Mucinous Neoplasm: A Case Report

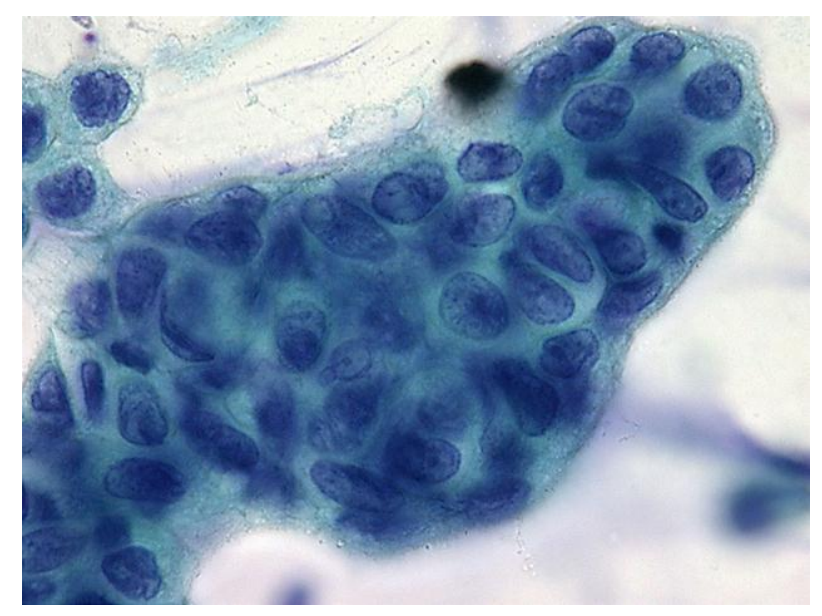

Fig. 2. The atypical columnar cells had loss of polarity, enlarged and hyperchromatic irregular nuclei and partially intracytoplasmic mucin.

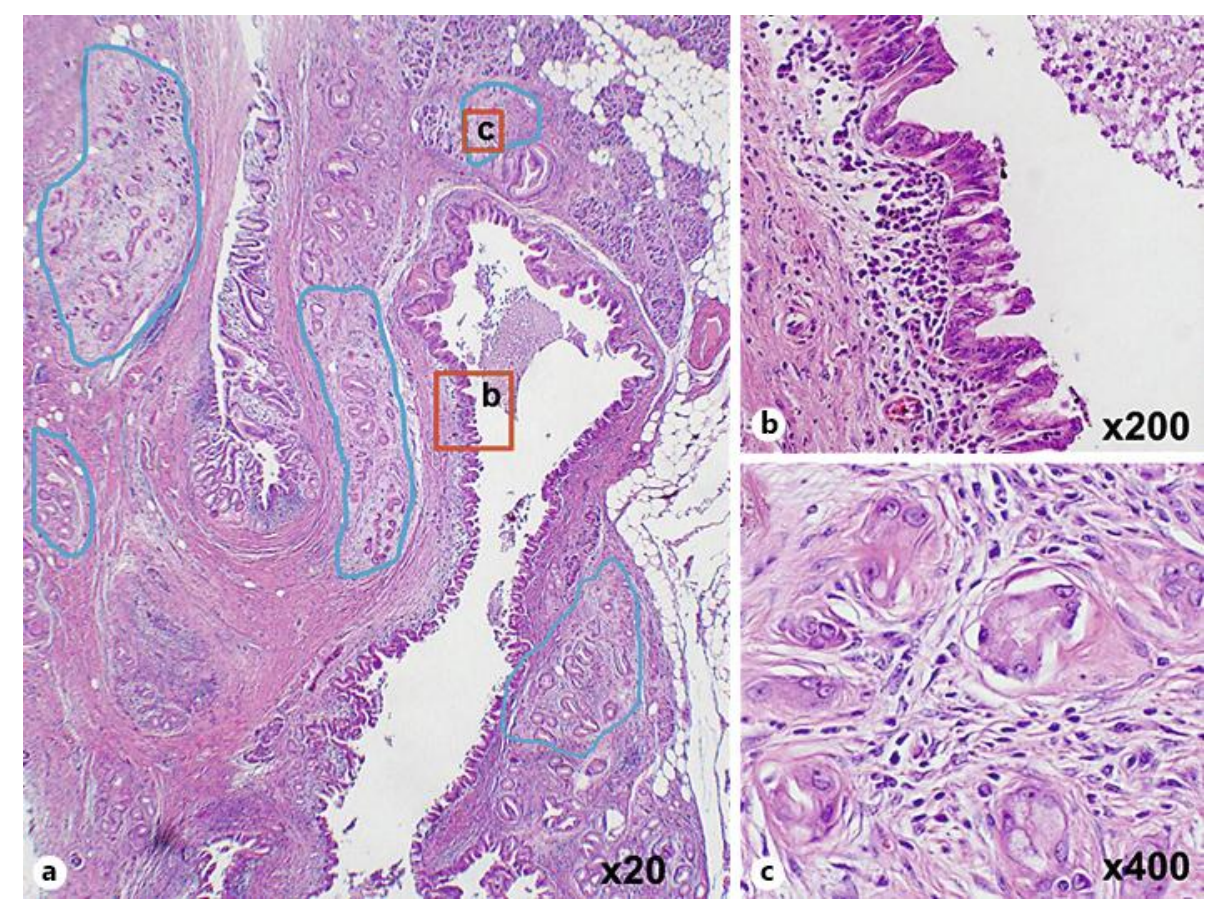

Fig. 3. Hematoxylin and eosin staining (original magnifications: $\mathbf{a} \times 20, \mathbf{b} \times 200, \mathbf{c} \times 400$ ). $\mathbf{a}$ Low-power field showed dilated branch ducts and small nests of invasive carcinoma surrounded by myxoid stroma (curved lines). Insets indicate images of the right side. $\mathbf{b}$ The dilated branch ducts were lined by mildly to severely dysplastic columnar epithelium. c Small nests of irregular glands with enlarged nuclei were invading the pancreatic parenchyma. 